\title{
The e-Portfolio as an Enabler for Work-integrated Learning in Universities of Technology
}

\author{
Aneen Koch \\ Cape Peninsula University of Technology, \\ Cape Town, South Africa
}

\section{kocha@cput.ac.za}

\begin{abstract}
Traditional portfolios submitted for work-integrated learning are submitted in formats such as files, boxes and/or binders holding papers have become an inefficient mechanism, taking up a lot of space and prove to be cumbersome as an enabler of learning. Typically, the work-integrated learning curriculum of universities of technology in South Africa world-wide requires a paper based document, generally referred to as a portfolio. The latter reflects the evidence of the student's practical experience. Some research has been done to address the shortcomings of traditional work-integrated portfolios, for example how to store learning evidence on computer. An electronic portfolio is a collection of electronic evidence assembled and managed by a user (in this case a student), usually via the Web. e-Portfolios demonstrates the user's ability to utilize web platforms for self-expression. Furthermore they can be maintained dynamically over time. The advantage of e-portfolio applications are that it can be accessed by various users (e.g. lecturing staff, employees, students) and for multiple purposes of teaching and learning. This paper establishes to what extent the electronic portfolio can be utilized to support the curricula of universities of technology to gain effective access to the learning record or evidence of students during and after work-integrated learning.
\end{abstract}

Keywords: Portfolios, e-portfolios, students, work-integrated learning, curriculum, assessment, university of technology

\section{Introduction}

The purpose of electronic portfolios is to stay focused on the quality of work by a student during work-integrated learning and the valid alignment of their work to the standards and goals of education. Portfolios have been part of the curriculum for a very long time. Long before the digital age, lecturers and students have used a paper-based portfolio system very successfully in the form of files, boxes and/or binders holding paper, cassettes, pictures, drawings. Since then e-portfolios have become an important tool to document the nature of the work of students, as well as demon-

Material published as part of this publication, either on-line or in print, is copyrighted by the Informing Science Institute. Permission to make digital or paper copy of part or all of these works for personal or classroom use is granted without fee provided that the copies are not made or distributed for profit or commercial advantage AND that copies 1) bear this notice in full and 2) give the full citation on the first page. It is permissible to abstract these works so long as credit is given. To copy in all other cases or to republish or to post on a server or to redistribute to lists requires specific permission and payment of a fee. Contact Publisher@InformingScience.org to request redistribution permission. strating the quality of learning that took place (American Association for Higher Education, 2008; Smith \& WinkingDiaz, 2004). Since 2005 a growing number of colleges and universities in the United States of America and various other countries are adopting eportfolios for teaching and learning (Lorenzo \& Ittelson, 2005a). Unlike paperbased portfolios, e-portfolios allow information to be continuously stored, 
accessed, updated, and presented in various electronic formats (Tubaishat, Lansari, \& Al-Rawi, 2009, p. 1). For a university of technology (UoT) such as the South African Cape Peninsula University of Technology (CPUT) the e-portfolio can be a more accurate system to manage, review, reflect, assess and to comment on the students' work, during and after work-integrated learning.

\section{The Work-integrated Learning Concept}

Within the South African university of technology's context, co-operative education is a careerorientated educational system in which each qualification also prescribes an accredited experiential learning component. Career-orientated education comprises the divulging of knowledge, the transfer of skills, and the inculcating of values and attitudes of a utilitarian nature, particular to careers (Heinemann, DeFalco, \& Smelkinson, 1992, p. 18). It is therefore aimed at preparing a student, without additional in-service training, as useful manpower from the very outset of employment. This initial training within the "real world of work" is provided through the workintegrated learning component of co-operative education.

Work-integrated learning is an extension of the formal educational component of tuition normally provided by the UoT. It may assume various forms to reach the objective to facilitate learning in the real world-of-work. It also extends to the student the opportunity for experiential performance within this environment. Implicit in these concepts is purposeful monitoring. It is therefore preferable to include or reflect any achievement(s) attained during work-integrated learning in the candidate's final performance evaluation (Heinemann et al., 1992, p.19).

Managing work-integrated learning, which is not always structured into fixed time periods during a semester, term or academic year, or prescribed text and rigid syllabi, and which normally takes place outside the traditional academic environment within the ambit of commerce and industry, requires a well-designed management strategy.

\section{CDL \& WiL: Looking from both sides of the two-way mirror}

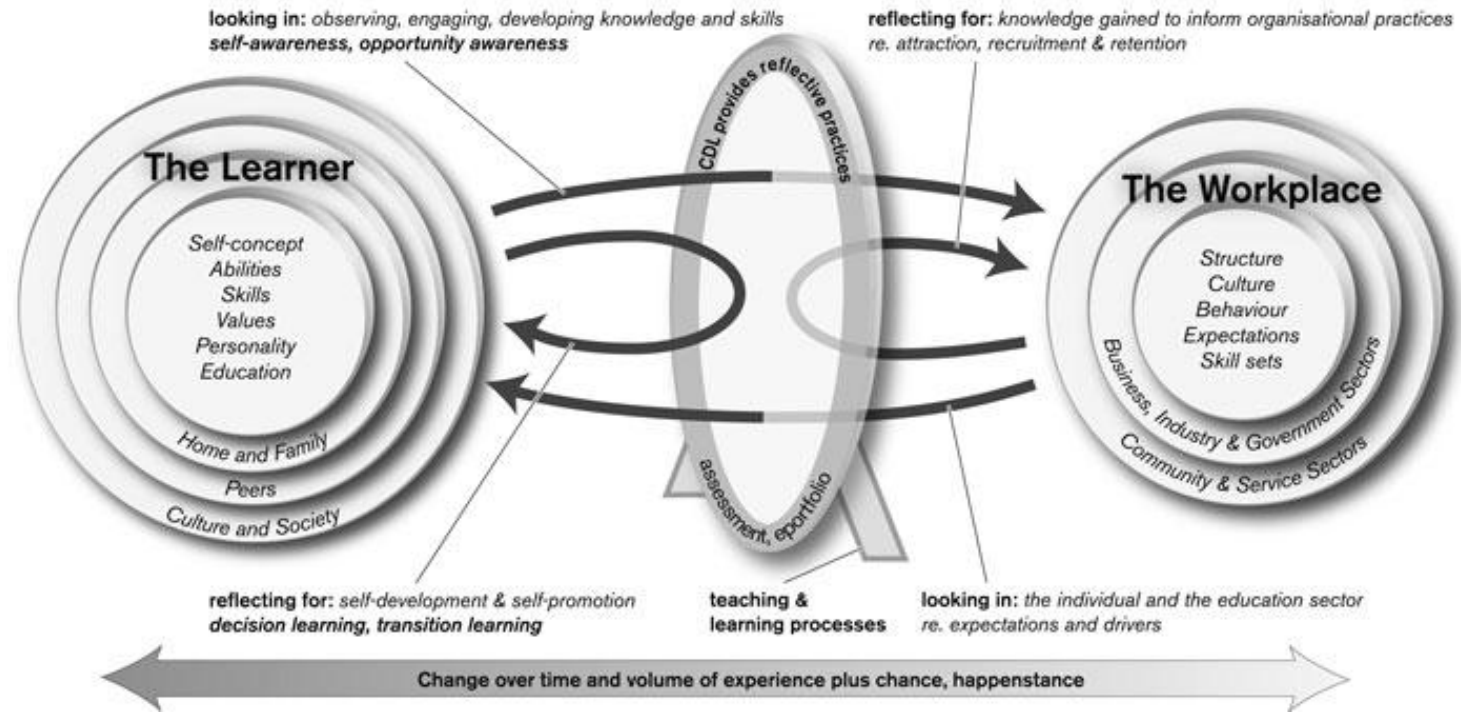

(Adapted from Career development learning and work-integrated learning, 2010)

Figure 1: Career development learning and work-integrated learning

Most students only realize the value and applicability of their career choice once they are employed by industry. This process is illustrated in Figure 1 which put the emphasis on a career de- 
velopment learning process as well as work-integrated learning process which should result in a successful completion of the student's industry exposure and training.

\section{Unique Purpose of the Portfolio in General}

Within most UoTs in South Africa, the curriculum subject work-integrated learning is compulsory within most of the academic qualifications of these institutes (experiential learning is a synonymous term). As a reflection of the student's exposure within industry, a wide range of assignments, portfolios, logbooks, and any other formats need to be submitted to the course lecturer for assessment.

The outcomes of these work-integrated learning portfolios include assignments, logbooks, CVs, diaries, pamphlets and any other formats. In a nutshell the outcomes serve the following purposes: for

- Learning - ongoing professional development by the student

- Assessment - formal evaluation process of the student's work by the lecturer

- Employment - consulted by the employer when a student seeks employment.

Furthermore, work-integrated learning implies that students should be involved in meaningful performances, tasks, and learning areas which is set out clearly by the UoT that will contribute towards student outcome of high quality. As the final outcome of the work-integrated learning process, the portfolio as well as performance appraisal should be assessed by the employer and the accredited assessor (moderator) or in some cases, the lecturer himself.

\section{From Paper-based to Electronic-Portfolios}

\section{Defining the e-Portfolio}

Hardcopy or paper-based portfolios have been around since the 1950s, but e-portfolios only came to the fore during the last two decades. Whilst the hardcopy portfolio consists of a multitude of different types of documents (for example a CV, assignments) the e-portfolio combines the use of electronic technologies to create, publish and maintain a multiple document system via a webbased approach.

The Office of Learning Technology website (University of British Columbia, n.d.) defines eportfolios as personalized, web-based collections of work, responses to work and reflections that are used to demonstrate key skills and accomplishments for a variety of contexts and time periods. Furthermore, Barrett (2002) formulates the following definition of an e-portfolio:

"A portfolio is a purposeful collection of student work that exhibits the student's efforts, progress and achievements in one or more areas. The collection must include student participation in selecting contents, the criteria for selection; the criteria for judging merit, and evidence of student self-reflection."

In a later publication, Cotterill (2007) states that an e-portfolio is a collection of information in the form of digital artifacts, that can include evidences, learning outcomes, skills and competencies.

Although different authors have suggested their own definitions of the concept $e$-portfolio, for the purpose of this paper and especially in the UoT environment, the following working definition can be formulated: an e-portfolio is an electronic filing system or rather, an efficient Web-based management system for students to post or submit their academic work in the form of projects and assignments to reach the goals formulated for their academic work. This is done without the 
bulk and clutter of hardcopy or paper. An e-portfolio is not an e-portfolio if it does not contain reflections of the student's work and if it cannot be shared by employers, lecturers, and fellow students.

\section{Types of e-Portfolios}

Similar to traditional portfolios, e-portfolios can also be categorized into various types according to deliverables. Although Lorenzo \& Ittelson (2005b) categorize e-portfolios according to three broad groups, namely student, teaching and institutional e-portfolios, Auld (n.d.) and Brown (2002) prefer to use the following types of e-portfolios commonly applied by tertiary communities worldwide:

- Assessment e-portfolio - presents the work demonstrating that the student has met specific learning goals and requirements.

- Display e-portfolio - showcases samples of the student's best work and achievements.

- Learning e-portfolio - document, guide and advance learning over time.

- Personal development e-portfolio - record learning and performance that can be reflected on, outcomes of that reflection, and future development plans.

- Working e-portfolio - projects the student is working on or has completed. It can also combine elements of all the above types and can include multiple views of each.

The choice of a particular type of e-portfolio will showcase the student's collection of outcome over a period of time and will contribute to serve as a marketing tool within several communities of practise.

\section{e-Portfolio Development}

Although not the purpose of this paper, it should be mentioned that basically two approaches or strategies to create or develop e-portfolios could be followed. They are:

- Generic tools approach, that is, to purchase and utilize off-the-shelf software specially developed for various teaching and learning management applications.

- Customized systems approach, which implies designing a system from start with applicable software but was not developed specifically for e-portfolios.

Although it is eminent that there are a variety of tools to develop electronic portfolios, the input process, that is, from the end-user or student's point of view, should be kept as user-friendly as possible. The most important objective should be that an electronic portfolio should reflect the student's achievements and capabilities within industry and also, to support lifelong learning.

Before a e-portfolio can be implemented by a UoT and especially incorporated into the workintegrated learning curriculum, a comparison should be made between the generic tools approach and customized systems approach. Consideration should be given to the best strategy that will preserve the heart of the traditional, creative, reflective WIL portfolio. The results of such a comparison will create a clear understanding by the UoT of the e-portfolio decision making process, to recognize the trade-offs, as well as the strengths and weaknesses of the strategy. The following set of criteria was published by Barrett (2002); Gibson \& Barrett, (2003) and applied to UoTs by the author of this paper:

1. Planning and goal setting - Plan self-directed learning or setting goals, either by the workintegrated learning curriculum, the employer or the student, for example scheduling timelines, databases, spreadsheets. 
2. Framework for creativity - Student will be able to use own initiative and creativity skills for example audio, video, spreadsheets, databases.

3. Communications - Use of telecommunication between student, employer and lecturer for example e-mail, video conferencing, web blogs.

4. Collaboration tools - Collaboration between student, lecturer, faculty for e.g. video conferencing, threaded discussions, whiteboards, etc.

5. Reflective processes - Student reflect on artifacts as well as how they support the learning areas in work-integrated learning for example wordprocessing, video, audio, multi-media.

6. Connection capabilities - Should take advantage of the linking capabilities of digital technology, to make easy connections between various assignments, student's reflections and various learning areas for example, hypertext capabilities, web development applications.

7. Organizational flexibility - Students maintain various ways to organise their work exposure/work evidence and utilize multiple organization frameworks to represent their work evidence, for example hypertext databases Face Book.

8. Display flexibility and transportability - The flexibility of the system to display the eportfolio into multiple-formats for example drive storage, DVD, database driven displays, dynamic HTML.

9. Data and information - Work-integrated learning e-portfolios form part of the academic programme evaluations process and provide the opportunity to aggregate data across the various academic subjects, the WIL objectives and the students learning outcome, for example. databases, spreadsheets, web searches, virtual libraries.

10. Start-up costs and maintenance - E-portfolios should be cost-effective with a proper maintenance as well as support system which will be useful for the UoT, employer, academic and students, example servers, lab-licenses, system software.

By using the generic approach students may use whatever digital storage space they have available. Whereby the customized system approach, universities of technology must provide a teaching and learning management system that provides a structure and server space for the students to store, upload and structure their portfolios according to the work-integrated learning areas and curriculum guidelines.

According to Gibson and Barrett (2002) the challenge is to integrate both CS and GT into a comprehensive e-portfolio development programme. Gibson states further that the rich pictures of learning are as useful as highly comparable measures of performance (performance appraisal) and achievement (final outcome of the e-portfolio). Both these measures are needed for a deep understanding of students and a programme's impact on them.

Also, from a student's point of view the input phase within work-integrated learning should contribute to the professional development and life-long learning of students within industry. The work by Danielson and Abrutyn (1997) has been updated in a later publication by Attwell (2010) to describe how the process for developing an e-portfolio enfolds:

- Collection - Students to save artifacts that represent their learning areas, exposure, contribution, successes and gaining of knowledge in their day-to-day learning (logbooks or work records).

- Selection - Students review and evaluate the artifacts they have saved, and identify those that demonstrate learning achievement of specific work-integrated learning areas. 
- Reflection - Students become reflective practitioners, evaluating their own growth within their work integrated learning period and their achievement of the learning areas, as well as the gaps in their exposure within industry.

- Projection - On a weekly basis students compare their reflections to the learning areas as set out by the lecturer and performance indicators/appraisal, and set goals for the remaining period. This stage the portfolio development turns into professional development and supports life-long learning.

- Publish, present and link - Students share their portfolios with their peers (fellow students, employers, supervisors, lecturers, mentors) and present it to the UoT for final assessment of the academic subject applicable to the exposure gained in industry.

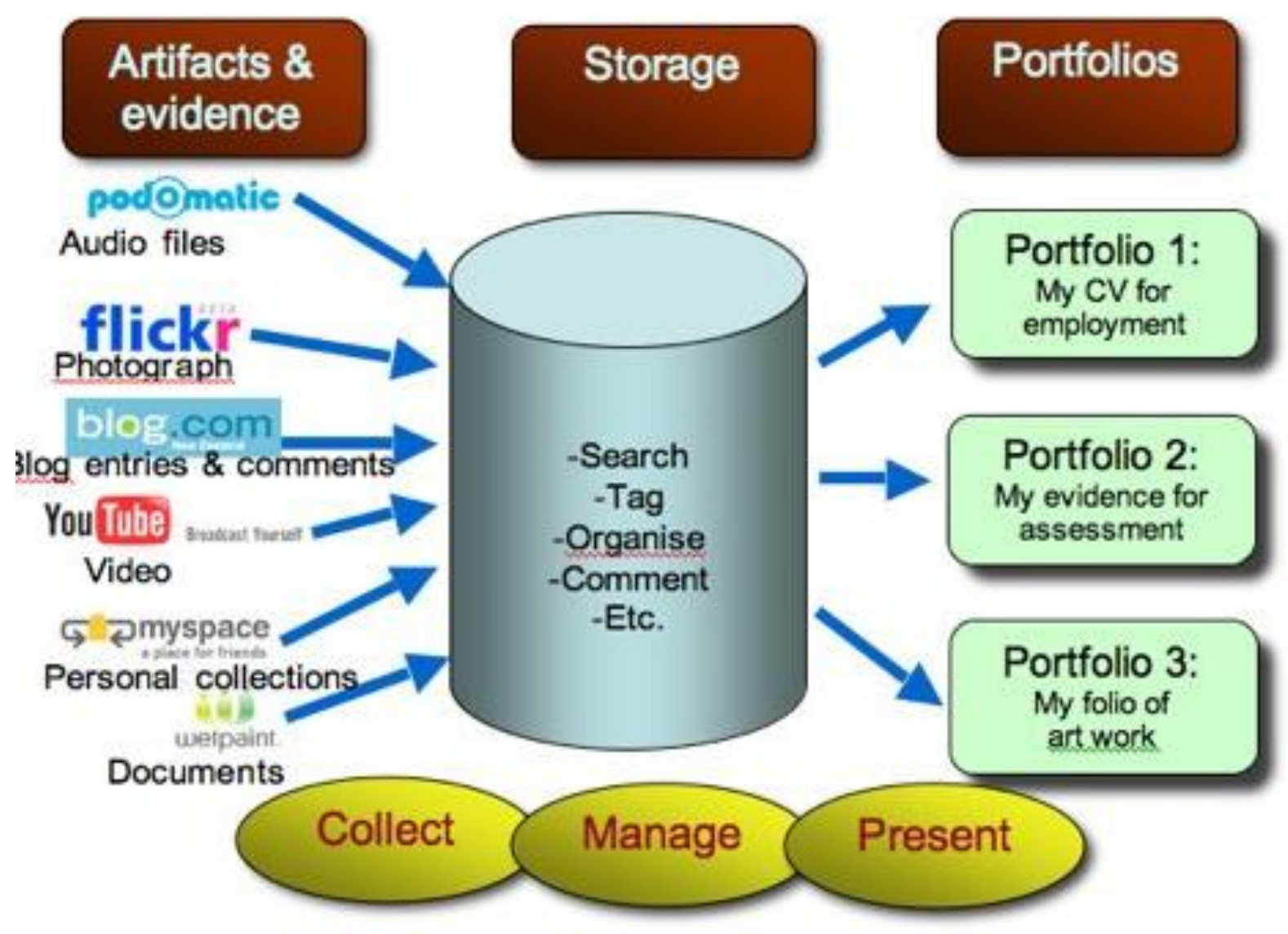

Figure 2: The portfolio process (Wenmoth, 2008)

The above discussion culminates effectively into Figure 2's reflection of the various phases of developing an e-portfolio while the student is within industry. The final phase will be completed within the last week of exposure (still within industry) when the students publish and submit their e-portfolio for assessment.

\section{e-Portfolio Prior Learning Assessment}

After completion and submission of an e-portfolio by a student, it needs to be assessed by the academic department of a UoT as prescribed and set out by the academic curriculum. As a guideline Wong (1996) identified already a decade ago five commonly underlying assumptions for prior learning assessment: 
- Learning occurs across the lifespan

- Learning takes place in various contexts, including formal, informal and non-formal

- Formal learning is not necessarily of greater significance than learning gained through other contexts

- Formal learning objectives can be used to reliably assess learning gained through other contexts

- When equivalent to formal learning, learning gained through other contexts should be recognized.

A further guideline in developing assessment of prior learning by a UoT, Romaniuk and Fern (2000) can be quoted as they support Wong in that prior learning assessment provides a means of comparing acquired learning through various contexts, namely formal, informal and non-formal context. Within a 'formal' context the academic model at the UoT takes place within an academic programme (certificate, diploma, degree). Informal learning is directed by industry (workintegrated learning) whilst non-formal learning is experienced by the student within industry during the work-integrated learning period.

Within the curriculum structure of the UoT work-integrated learning (WIL) is an academic subject with credits. Students need to register for the subject in their second or third year of academic studies, in order to qualify for exposure within industry. Due to its credit bearing weight, students must be assessed by an accredited assessor, invariably from industry, who is formally appointed. Prior learning assessment is done on the identification of that learning which took place within industry. The responsibility is with the student to identify and substantiate that learning took place according to the specified criteria for the work-integrated learning subject. The assessor will award an academic credit to the student's e-portfolio after final assessment, which will consequently contribute to the final academic qualification.

The above discussion forms the basis of an in-depth investigation by this researcher to establish the feasibility of availing e-portfolios for work-integrated learning at CPUT. The starting point of this project was to establish the perceptions of stakeholders in the CPUT environment with regard to the feasibility of e-portfolios for WIL (work integrated learning). Based upon the current international situation discussed above, and apparent lack of e-portfolio applications by typical UoTs, it was decided to introduce the concept to its stakeholders, as well as establish the potential value of e-portfolios in the typical UoT's teaching and learning environment. Because of its informal nature and scope for brainstorming this researcher decided to utilize the Nominal Group Technique (NGT) (MacPhail, 2001) to establish the perceptions of the following three stakeholders at CPUT; the procedure to select 10 individuals for each session is explained as follows:

- Academic staff / lecturers: top ten users of Blackboard, CPUT's official teaching and learning system. The individuals were selected according to the highest number of hours an individual spent on Blackboard during the last four months of classes of the 2009 academic year.

- Students: Ten students, based upon the first ten who received permanent employment after completion of their WIL degree course.

- Employers (industry): The top ten employers who appointed the largest number of students in 2009 for their compulsory WIL experience.

The NGT process enfolded as follows:

- Extensive Web-searching for good examples of e-portfolios was done, illustrating as many applications and formats of evidence as possible. 
- A selection of the best examples of e-portfolios was downloaded - those applications that will best apply in a WIL environment were identified and earmarked for demonstrations to the three groups.

- Each stakeholder group met separately and the following question formulated and displayed in large font to each group: 'What is your perception of the advantages in using an e-portfolio in work-integrated learning?'

- Each of the group received five minutes to write down as many strong points or rather perceptions in using e-portfolios. Each member was requested to put the list in priority order from very important to less important.

- Individuals were then given the opportunity to read only one from his/her list (always starting at the top of the list). No motivation or discussion is allowed at this stage. This is repeated until all the lists were read and written on a white board or pasted to a wall.

- Brief discussion of each response is now allowed by the respondent who listed an item. It turned out that most of the items listed were self-explanatory.

- To conclude, the group then voted for the top five answers listed - these become the perceptions of the group with regard to the feasibility to use e-portfolios. The three lists of perceptions are given below.

Below are the six most important perceptions of an e-portal as listed by the three groups when implemented within a WIL environment.

\section{Perceptions of academic staff working with WIL portfolios}

- Research opportunities associated with WIL activities are significant

- Provide academic staff with the time and resources to interact with relevant industrial, commercial and public sector employers to enable them to increase their contacts and capitalise on their knowledge of the field

- Ensure effective communication between UoT and potential employers about work experience opportunities and practices.

- Integrate student learning experiences with curriculum development

- Use web-based links to encourage employers to participate in course validation panels in the development of subject areas, to present guest lectures or participate in student seminars

- Develop expertise in assessment methods by working with employers who have experience in assessing “employability” skills

\section{Perceptions of students working with WIL portfolios}

- Provides direct access to different subjects as well as WIL subject guides

- Simplifies completion and uploading of compulsory WIL forms and work records (log books) during the WIL phase

- Provides immediate access to the results of other academic and specific WIL-related assessment results

- Facilitates with the buy-in of employers via CVs, academic results, community involvement and/or special projects

- During the WIL period assignments, log books, work records, and any other deliverables can 
be upload off-campus

- Interview results can be posted via the system as soon as a decision has been made by employers.

\section{Perceptions of participating employers working with WIL e-portfolios}

- Provides access to graduates' online e-portfolios for recruitment purposes

- Avails the electronic CVs of potential WIL students

- Enhances links with the UoT to feed into teaching practices and methodologies

- Creates staff development opportunities that arise from employees who mentor students

- Creates links with UoT to assist in developing a learning culture with industry and commerce via short courses

- Employers can assess portfolios and performance appraisal online.

\section{Conclusion}

In this paper an overview was given of the status quo of the concepts of work-integrated learning (WIL), the nature and important role of traditional or rather hardcopy portfolios. This formed the backdrop of deliberations on the transformation of the paper portfolio into a digital or electronic portfolio that consists of the full component of a WIL student's prescribed deliverables, such as a frequently updated $\mathrm{CV}$, research projects, technical reports, work records, assessment forms, video, sound and other multimedia files. The development phases of the e-portfolio were touched upon, as well as a categorization of the various categories of e-portfolios. To conclude, the first phase of a research project on the feasibility of e-portfolios within the UoT's WIL environment was introduced. The purpose of this introductory phase was to establish the perceptions of the stakeholders with regard to e-portfolios as instrument for life-long learning. The overall finding or outcome of the Nominal Group Technique brain storming sessions arranged by this author indicated an overwhelming positive response towards the advantages of e-portfolios in the UoT's academic structure, with special emphasis on work-integrated learning.

Further research is essential with regard to the most efficient teaching and learning management system within a WIL environment, unique nature of e-portfolios in a UoT, strategies to sell the principle of e-portfolios the different stake holders, including management. Last but not least, principles of designing a strategy to enable a student to develop his/her portfolio for life-long learning purposes.

\section{References}

American Association for Higher Education. (2008). Electronic portfolios: Practices for students, faculty and institutions. Retrieved February 25, 2010 from http://ahe.ital.utexas.edu/electronicportfolios/index.html

Attwell, G. (2010). Rethinking e-portfolios. Pontydysgu - Bridge to learning. Retrieved April 23, 2010 from http://www.pontydysgu.org/2010/03/rethinking-e-portfolios/

Auld, P. (n.d). Creating and using portfolios on the alphabet superhighway. Retrieved February, 2, 2010 from http://www.ash.udel.edu/ash/teacher/portfolio.html

Barrett, H. (2000). Create your own electronic portfolio. Learning \& Leading with Technology, 27(7), 1421. 
Barrett, H. (2002). Presentation, ISTE's Forum on Assessment and Technology, San Antonio, TX, June 14, 2002.

Brown, M. (2002). Electronic portfolios in the K-12 classroom. Education World. Retrieved September, 25, 2009 from http://www.educationalworld.com/a tech/tech/tech111.shtml

Career development learning and work-integrated learning. (2010). Retrieved, March, 14, 2010 from http://www.nagcas.org.au/ALTC/about-this-project/model

Cotterill, S. J. (2007). What is an e-portfolio? E-Portfolios conference. Maastricht. Retrieved, 20 April 2010 from http://www.eportfolios.ac.uk/definition

Danielson, C., \& Abrutyn, L. (1997). An introduction to using portfolios in the classroom. Alexandria: Association for Supervision and Curriculum Development.

Gibson, D., \& Barrett, H. (2002). ITForum Paper \#66. Directions in electronic portfolio development. Retrieved February, 2, 2010 from http://it.coe.uga.edu/itforum/paper66/paper66.htm

Gibson, D., \& Barrett, H. (2003). Directions in electronic portfolio development. Contemporary Issues in Technology and Teacher Education, 2(4), 559-576.

Heinemann, H. N., DeFalco, A. A., \& Smelkinson, M. (1992). Work-experience enriched learning. The Journal for Co-operative Education, 28(1), 17-33.

Lorenzo, G., \& Ittelson, J. (2005a). Demonstrating and assessing student learning with e-portfolios. The Educause Learning Initiative, October 2005. Retrieved April 23, 2010 from http://net.educause.edu/ir/library/pdf/ELI3003.pdf

Lorenzo, G., \& Ittelson, J. (2005b). An overview of e-portfolios. The Educause Learning Initiative, July 2005. Retrieved March 19, 2010 from http://net.educause.edu/ir/library/pdf/ELI3001.pdf

MacPhail, A. (2001). Nominal Group Technique: A useful method for working with young people, British Educational Research, 27, 2.

Romaniuk, K., \& Fern, S. (2000). Enhancing employability: The role of prior learning assessment and portfolios. Journal of Workplace Learning: Employee Counselling Today, 12(1), 29-34. Retrieved February, 2, 2010 from http://www.emeral-library.com

Smith, M., \& Winking-Diaz, A. (2004). Increasing students' interactivity in an on-line course. The Journal of Interactive Online Learning, 2(3), 1-25. Retrieved February 17, 2010 from http://www.ncolr.org/jiol/issues/PDF/2.3.3pdf

Tubaishat, A., Lansari, A., \& Al-Rawi, A. (2009). E-portfolio assessment system for an outcome-based information technology curriculum. Journal of Information Technology Education: Innovations in Practice, 8, 43-54. Retrieved from http://www.jite.org/documents/Vol8/JITEv8IIP043054Tubaishat710.pdf

University of British Columbia. (n.d.). Personal publishing and e-portfolios. Retrieved April 22, 2010 from http://olt.ubc.ca/learning-tools/eportfolios

Wenmoth, D. (2008). Conceptualising e-portfolios. Retrieved April 13, 2010 from http://blog.core-ed.net

Wong, A.T. (1996). Prior learning assessment: A guide for university faculty and administrators. University Extension Press, University of Saskatchewan, Saskatoon. 


\section{Biography}

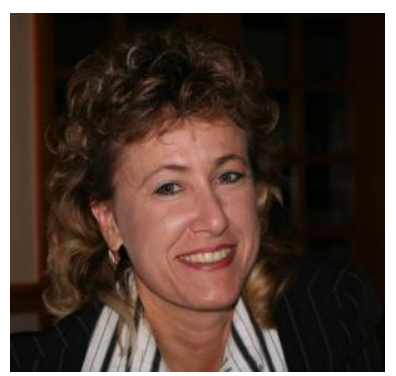

\section{Dr. Aneen Koch}

Current Occupation: Co-operative Education Lecturer

Qualifications: Doctor Technologiae : Office Management \& Technology, obtained in 2008 at the Cape Peninsula University of Technology, Cape Town, South Africa

Title: A conceptual model for a co-operative education management information system for tertiary institutions in South Africa

Conferences/workshops: Participate actively annually in workshops, forum discussions, national as well as international conferences.

Current research: The changing demands of Higher Education internationally, but especially in South Africa is an uncompromising fact. In the course of my recent research I examined the use of e-portfolios at Universities of Technology, and garnered the views of educators, employers, students and administrators involved in work-integrated learning. This research will establishes to what extent the electronic portfolio can be utilized to support the curricula of universities of technology to gain effective access to the learning record or evidence of students during and after work-integrated learning. 